\title{
La biolixiviación al comienzo del siglo XXI(•)
}

\author{
Y. Rodríguez*, M.L. Blázquez*, A. Ballester*, F. González* y J.A. Muñoz* \\ Resumen La biolixiviación se presenta actualmente como una de las técnicas del futuro para el \\ tratamiento de concentrados minerales sulfurados, debido a sus ventajas ampliamente \\ reconocidas. De forma natural, con bajos costes y sin deteriorar el medio ambiente, permite \\ la recuperación de metales a partir de minerales, sobre todo de baja ley y refractarios, \\ compitiendo con los procesos de extracción convencionales. Durante la última década se \\ ha investigado bastante en el conocimiento a nivel básico del proceso. Se ha avanzado en \\ los aspectos bioquímicos, genéticos y moleculares de los microorganismos implicados; en el \\ diseño, implementación y mejora del proceso; en el conocimiento de los factores físico- \\ químicos que influyen en el rendimiento; y en la utilización de iones catalizadores para \\ mejorar la disolución. Esta revisión bibliográfica pretende resumir la historia de la \\ biolixiviación y su base microbiológica e indicar su estado actual y el posible desarrollo \\ futuro que tendrá esta técnica.
}

Palabras clave Biohidrometalurgia. Biolixiviación. Sulfuros metálicos. Bacterias acidófilas.

\section{Bioleaching at the beginning of the $21^{\text {st }}$ century}

\begin{abstract}
Bioleaching is one of the most promising techniques for the treatment of sulfide concentrates on the basis of its advantages widely recognized. It allows the recovery of metals from different ores (especially low-grade and refractory ones) in a natural way, with low costs and in a friendly manner with respect to the environment, competing with conventional extractive processes. During the last decade research has focused on basis knowledge of the process. Advances have been made in biochemical, genetic and molecular aspects of the microorganisms involved in the process, and in the design and improvement of the process by a better knowledge of physical-chemical factors affecting the yield of the process, and the use of catalytic ions which improve dissolution. This bibliographical revision seeks to summarize the history of the bioleaching and its microbiological base, and also to indicate its current state and possible future developments that will take place.
\end{abstract}

Keywords Biohydrometallurgy. Bioleaching. Metal sulfides. Acidophilic bacteria.

\section{BIOLIXIVIACIÓN}

El progreso de la civilización ha requerido de los materiales metálicos para distintos usos comerciales, mejorando con éstos el bienestar social. Desde los métodos mineros de las edades prehistóricas a los actuales, son muchas las técnicas innovadoras que se han ensayado para mejorar su producción. Sin embargo, a partir de la década de los años setenta, la metalurgia extractiva ha tenido que en- frentarse con una fuerte crisis, principalmente como consecuencia del incremento de los costes de la energía y de la mano de obra, la cada vez más baja ley de las menas naturales y el agotamiento de las reservas. Por ello, ha sido necesario buscar materias primas minerales diferentes, entre las que cabe destacar los sulfuros metálicos. Las estimaciones aproximadas de reservas de metales valiosos que entran a formar parte de los sulfuros metálicos, para los yacimientos mundiales, son bastante

(•) Trabajo recibido el día 2 de octubre de 2000 y aceptado en su forma final el día 5 de marzo de 2001.

${ }^{*}$ ) Depto. de Ciencias de los Materiales e Ingeniería Metalúrgica, Facultad de Ciencias Químicas, Universidad Complutense de Madrid. 28040 Madrid (España). Fax: (34) 913944357.E-mail: Ambape@eucmax.sim.ucm.es 
considerables; por esta razón, se justifica cualquier tipo de esfuerzo investigador que se haga en la búsqueda de nuevas tecnologías alternativas para su tratamiento.

Los sulfuros presentan unas características adecuadas para la extracción, por métodos pirometalúrgicos, de los metales que contienen, ya que son fácilmente concentrables y el azufre suministra parte de la energía necesaria para la obtención del metal. Sin embargo, estos procesos son altamente contaminantes por las emisiones de $\mathrm{SO}_{2}$ que producen, contribuyendo al problema de la lluvia ácida. Como consecuencia de la política medioambiental existente y de la necesidad de reducir los elevados costes de inversión y de operación que conllevan los procesos convencionales, surgen los procesos hidrometalúrgicos como una alternativa novedosa. No obstante, éstos también presentan desventajas que han incidido negativamente en el desarrollo e implantación de estos procesos a escala industrial, entre las que destacan el elevado consumo de reactivos lixiviantes, las altas presiones y temperaturas que a menudo se requieren, y los elevados costes de operación de la molienda fina. En las últimas décadas ha surgido la Biohidrometalurgia, y dentro de ella la Biolixiviación, como un tratamiento alternativo prometedor. En la tabla I se muestran algunos de los procesos bio e hidrometalúrgicos más representativos para la recuperación de metales a partir de sulfuros metálicos.

El proceso de biolixiviación se produce por la catálisis que los microorganismos ejercen durante la disolución de algunas menas minerales. El microorganismo usa el mineral como combustible, utilizando la transferencia de electrones para sus propios propósitos de supervivencia, y liberando metales, sin requerir una aplicación externa de energía, al contrario de lo que hacen comúnmente

Tabla I. Procesos alternativos de recuperación de metales a partir de sulfuros metálicos

Table I. Metal recovery's alternative process from metal sulfides

\begin{tabular}{lc}
\hline \multicolumn{1}{c}{ Técnica } & Proceso \\
\hline Medio cloruro & BOLIDEN \\
Medio sulfato & COMPREX \\
Biológico-químico & BRISA, IBES \\
Biológico & SMP, BIOX ${ }^{\circledR}$, BioNIC ${ }^{\circledR}$, BacTech, GEOCOATTM \\
\hline
\end{tabular}

los humanos en el ciclo de uso de los materiales. En este tipo de procesos no son necesarias altas energías de activación; una prueba de ello es que las reacciones transcurren a baja presión y baja temperatura. En resumen, se puede decir que la lixiviación bacteriana o biolixiviación es el ataque y solubilización de un mineral a través de la acción directa o indirecta de distintos microorganismos.

En cuanto a las ventajas que presentan estos procesos frente a los clásicos piro o hidrometalúrgicos, Decker ${ }^{[1]}$ señala como más importantes las siguientes:

- Tienen lugar en condiciones cercanas a las ambientales, los compuestos utilizados no son ajenos a los ciclos biogeoquímicos y, por lo tanto, los productos y subproductos que se forman son más compatibles medioambientalmente.

- No se producen emisiones de $\mathrm{SO}_{2}$ como en los procesos pirometalúrgicos, con lo que se evita la contaminación ambiental provocada por las emisiones de este gas (lluvia ácida). Tampoco se produce contaminación por anhídrido sulfuroso, lo cual es frecuente en algunos procesos hidrometalúrgicos.

- Se reduce el consumo energético, puesto que no es preciso secar los minerales, como ocurre en los procesos pirometalúrgicos, ni alcanzar temperaturas elevadas (cercanas a $1.500^{\circ} \mathrm{C}$ ), ya que estos procesos tienen lugar generalmente a temperaturas próximas a la ambiente y en algunas ocasiones a temperaturas cercanas a $70^{\circ} \mathrm{C}$.

- Bajo consumo de reactivos, ya que en las reacciones biológicas se regeneran tanto el agente de lixiviación (ión férrico), como el ácido sulfúrico necesario para conseguir la acidez adecuada.

- Bajos costes de instalación y operación, ya que se requieren instalaciones más sencillas y económicas; por ejemplo, en el caso del cobre los costes pueden llegar a ser la mitad de los necesarios para obtenerlo por vía pirometalúrgica.

- Flexibilidad en las instalaciones, que permite hacerlas rentables incluso trabajando a escalas reducidas.

- Posibilidad de tratamiento de productos residuales y menas pobres que no son económicamente rentables, tratadas a través de procesos pirometalúrgicos e hidrometalúrgicos convencionales.

- Con respecto a los procesos hidrometalúrgicos de ataque químico convencionales, presenta la ventaja de que la acción química y biológica 
del medio permite la disolución de metales que por encontrarse en una matriz muy poco porosa, no serían accesibles al reactivo utilizado a menos que se realizara una molienda a tamaños de partícula muy reducidos. Las bacterias, al disgregar la matriz, solucionan este problema.

Evidentemente la lixiviación bacteriana también tiene desventajas, que en muchos casos han limitado su comercialización a escala industrial. Podemos señalar como desventajas más importantes:

- Velocidades de reacción lentas. A pesar de que las bacterias catalizan las reacciones de oxidación, la duración de los procesos es todavía muy larga.

- Obtención de soluciones demasiado diluidas para obtener el metal directamente a partir de ellas.

- Las aguas ácidas que se generan en estos procesos deben ser tratadas antes de su vertido, aunque generalmente se trabaja en ciclo cerrado y se recirculan al proceso.

\section{MICROORGANISMOS IMPLICADOS EN LOS PROCESOS DE BIOLIXIVIACIÓN}

La principal característica de los microorganismos utilizados en la recuperación de metales es su capacidad para evolucionar en ambientes con temperaturas, $\mathrm{pH}$ y condiciones de vida muy agresivas. Así, los microorganismos implicados en estos procesos son bacterias acidófilas capaces de sobrevivir a muy bajos niveles de $\mathrm{pH}$, altas temperaturas, altas concentraciones de elementos metálicos, y cuya fuente energética la constituye la oxidación de $\mathrm{Fe}^{2+}$ a $\mathrm{Fe}^{3+}$ y de compuestos reducidos de azufre. Estas bacterias se aislan, generalmente, de lugares donde ocurre la oxidación natural de minerales, como minas, aguas de manantiales ricas en azufre y depósitos de carbón.

En la recuperación de metales por biolixiviación, la principal acción de los microorganismos es la oxidación directa, mediante un ataque enzimático, o indirecta, mediante la regeneración del agente lixiviante $\mathrm{Fe}^{3+}$, de los metales contenidos en los minerales. Dicha acción aporta a las células la energía necesaria para sus reacciones metabólicas. En algunos casos, las bacterias contribuyen al desgaste de la ganga liberando el mineral valioso y facilitando su posterior ataque, ya que el ácido sulfúrico generado por las bacterias produce una ruptura de los enlaces $\mathrm{Si}-\mathrm{O}$ y $\mathrm{Al}-\mathrm{O}$ en los aluminosilicatos de la ganga mineral ${ }^{[2]}$.

Las bacterias acidófilas capaces de atacar sulfuros minerales se clasifican de acuerdo al intervalo de temperatura en el que crecen y se desarrollan, distinguiéndose tres grupos: mesófilas, termófilas moderadas y termófilas extremas.

\subsection{Bacterias mesófilas}

Las bacterias mesófilas tienen un rango de temperatura entre $25^{\circ} \mathrm{C}$ y $45^{\circ} \mathrm{C}$. Entre ellas se encuentran las bacterias autótrofas, obligadas que utilizan el anhídrido carbónico para satisfacer sus requerimientos biosintéticos de carbono (fuente inorgánica de carbono); las bacterias heterótrofas, que lo obtienen de fuentes orgánicas, y las bacterias mixotróficas, que lo obtienen de ambas fuentes, orgánica e inorgánica ${ }^{[3]}$.

Así, en los procesos de biolixiviación en montones,' en pilas o in-situ, se utilizan floras nativas de microorganismos constituidas por asociaciones de bacterias acidófilas autótrofas, heterótrofas o mixotróficas, hongos y algunos protozoos. Las bacterias autótrofas son las principales promotoras de la lixiviación de metales, mientras que el papel principal de las bacterias heterótrofas y de los protozoos es limitar la concentración de compuestos orgánicos que podrían, de otro modo, inhibir la acción de las autótrofas. Igualmente, se ha señalado la labor de control de la población que desarrollan los protozoos, mediante la depredación ${ }^{[4-6]}$. Las bacterias heterótrofas más comúnmente aisladas pertenecen al género Acidiphilium y, por lo general, se encuentran estrechamente asociadas a las autótrofas obligadas. También se han aislado bacterias heterótrofas facultativas dentro de las que se encuentran Thiobacillus acidophilus y Thiobacillus cuprinus $^{[7]}$.

Se ha observado que la disolución de la pirita mejora cuando L. ferrooxidans crece junto a bacterias del género Acidiphilium. Esta acción beneficiosa se debe a que estas últimas procesan y excretan una exoenzima que degrada los exopolímeros producidos por L. ferrooxidans, con el objeto de adquirir su fuente predilecta de carbono, la glucosa, generando así áreas libres en la superficie mineral a las que pueden acceder otras células, adherirse e incrementar la proporción de ellas que, potencialmente, atacan al mineral ${ }^{[8]}$.

Entre las bacterias mesófilas autótrofas obligadas más frecuentemente aisladas en ambientes mineros destacan: Thiobacillus ferrooxidans, 
Thiobacillus thiooxidans, y Leptospirillum ferrooxidans (Tabla II) ${ }^{[9]}$. Éstas, debido a sus similitudes fisiológicas y ambientales, se encuentran en los ambientes naturales de biolixiviación, coexistiendo simultáneamente y cooperando en el ataque de los minerales. Las dos primeras son bacilos, mientras que la última es un espirilo. Thiobacillus ferrooxidans normalmente se presenta en forma de células aisladas, aunque también son frecuentes las asociaciones en parejas; en cuanto a Leptospirillum ferrooxidans es capaz de formar espirales por unión de varias células y es mucho más larga que los thiobacilli.

La mayor diferencia entre las tres bacterias se encuentra en su capacidad para utilizar el ion ferroso y/o los compuestos reducidos del azufre como fuente de energía. $T$. ferrooxidans es capaz de utilizar tanto el $\mathrm{Fe}^{2+}$ como los compuestos de azufre como donantes de electrones, mientras que $T$. thiooxidans solamente es capaz de utilizar el azufre reducido, y $L$. ferrooxidans el ion ferroso. Los tres tipos de bacterias usan el oxígeno como aceptor terminal de electrones, aunque también se ha observado que $T$. ferrooxidans es capaz de sobrevivir utilizando el $\mathrm{Fe}^{3+}$ como aceptor de electrones y el azufre reducido como donante de electrones ${ }^{[10-12]}$.

Estas bacterias poseen requerimientos nutricionales muy sencillos. La aireación de una muestra de pirita en agua acidulada es suficiente para favorecer el crecimiento de $T$. ferrooxidans y $L$. ferrooxidans, ya que el aire les proporciona el carbono, nitrógeno y oxígeno necesarios para su crecimiento. La pirita es su fuente energética y el agua ácida el ambiente propicio para su crecimiento.

Se ha observado que, teóricamente, aquellos iones metálicos que existen en más de un estado de oxidación y poseen un potencial redox menor que el del par $\mathrm{O}_{2} / \mathrm{H}_{2} \mathrm{O}$, pueden servir como donantes de electrones para el crecimiento de estas bacterias biolixiviantes. Así, de acuerdo con la bibliografía,
Thiobacillus ferrooxidans es capaz de oxidar directamente el $\mathrm{U}^{4+}$ a U${ }^{6+}[13], \mathrm{Cu}^{+}$a $\mathrm{Cu}^{2+}\left[14\right.$ y 15], $\mathrm{Mo}^{5+}$ a $\mathrm{Mo}^{6+[16-18]}$ bajo condiciones aerobias, y esta reacción de oxidación se encuentra acoplada a la fijación de dióxido de carbono. Sin embargo, cada vez que el hierro se encuentra presente en estos sistemas de oxidación, se prefiere hablar de un mecanismo de oxidación directo e indirecto que actúa a la par, debido a que el $\mathrm{Fe}^{3+}$ generado por las bacterias mediante la oxidación de $\mathrm{Fe}^{2+}$, es capaz de oxidar químicamente a estos metales. También se ha indicado que $T$. ferrooxidans es capaz de oxidar arsenopiritas. La gran versatilidad de este microorganismo en la oxidación de metales ha sido ampliamente estudiada y reconocida, mientras que en el caso de T. thiooxidans y L. ferrooxidans aún falta mucho por estudiar y dilucidar.

\subsection{Bacterias termófilas}

Dentro de los microorganismos que actúan en los procesos de biolixiviación es imprescindible hacer una mención especial de los microorganismos termófilos. Se caracterizan por vivir y reproducirse en ambientes ácidos, a temperaturas que se encuentran en el rango de 45 a $90^{\circ} \mathrm{C}$. Cada día cobra más fuerza la idea de su utilización en la biolixiviación de concentrados minerales, dado que estos permiten alcanzar grados de disolución y velocidades de lixiviación mucho más altas que aquellas obtenidas con bacterias mesófilas ${ }^{[19]}$. Así, la alta eficacia que se logra con estos microorganismos en la extracción de cobre de la calcopirita es, tal vez, la aplicación más importante de la biolixiviación a altas temperaturas. También se han conseguido excelentes resultados en la oxidación de piritas y arsenopiritas.

Este tipo de bacterias fueron aisladas por primera vez por Brierley, a mediados de los años 60 , en un manantial ácido de aguas termales en el Parque

Tabla II. Características de las bacterias mesófilas con capacidad lixiviante

Table II. Mesophile bioleaching microorganisms

\begin{tabular}{lcccc}
\hline Microorganismo & Tamaño y forma & $\mathbf{T ~}\left({ }^{\circ} \mathbf{C}\right)$ & $\mathbf{P h}$ & Fuente de energía quimiolitótrofa \\
\hline Thiobacillus & $0,3-0,5 \times 1-1,7 \mu \mathrm{m}$ & $5-40$ & $1,2-6,0$ & Oxida a Fe $\mathrm{F}^{2+} \mathrm{y} \mathrm{S}^{0}$ \\
ferrooxidans & Bacilo & $30-35$ óptima & $2,5-3$ óptimo & \\
Thiobacillus & $0,5 \times 1,2 \mu \mathrm{m}$ & $10-40$ & $0,5-6,0$ & Oxida $\mathrm{S}^{0}, \mathrm{no} \mathrm{a} \mathrm{Fe}^{2+}$ \\
thiooxidans & Bacilo & $30-35$ óptima & $2-3,5$ óptimo & \\
Leptospirillum & $0,2-0,4 \times 0,9-1,1 \mu \mathrm{m}$ & $20-45$ & $1,2-4,5$ & Oxida Fe $\mathrm{Fe}^{2+}, \mathrm{no} \mathrm{a} \mathrm{S}^{0}$ \\
ferrooxidans & Espirilo & $30-35$ óptima & $2,5-3$ óptimo & \\
\hline
\end{tabular}


Nacional Yellowstone (Wyoming, EE.UU.). Los resultados de estos primeros estudios fueron presentados por Brierley en 1966 en su Tesis Doctoral y se publicaron posteriormente en $1973^{[20]}$. Estudios posteriores a los iniciales de Brierley demostraron que el organismo era mixotrófico y morfológicamente diferente al Thiobacillus, al carecer de una pared celular rígida, poseer pilis en vez de flagelos y tener forma esférica. Estas bacterias termófilas incialmente recibieron el nombre de Sulfolobus brierleyi ${ }^{[21]}$; posteriormente fueron reclasificadas dentro del género Acidianus, y actualmente son conocidas como Acidianus brierleyi ${ }^{[22]}$.

Las especies del género Sulfolobus son capaces de crecer tanto de forma heterotrófica como autotrófica. Bajo condiciones autótrofas catalizan la oxidación de azufre elemental, $\mathrm{Fe}^{2+}$ y sulfuros minerales. Producen velocidades de biolixiviación de sulfuros metálicos muy altas, sobre todo cuando la concentración de sólidos o la densidad de pulpa es baja; mientras que en el caso contrario, cuando las densidades de pulpa son altas, su acción se ve altamente restringida ${ }^{[23]}$. En general, el grupo de microorganismos termófilos extremos presenta como principal problema la gran sensibilidad de su membrana frente a fenómenos de atrición, lo que obliga a utilizarlas en los procesos de lixiviación dinámica (reactores) con densidades de pulpa menores que las utilizadas en ensayos con microorganismos mesófilos ${ }^{[24]}$. Por esta razón, desde hace ya algunos años, se está implementando el uso de bacterias termófilas moderadas, que son más resistentes a altas densidades de pulpa, e incluso algunas también son muy resistentes a elevadas concentraciones de $\mathrm{Fe}^{2+}$. Adicionalmente, conllevan ventajas económicas en cuanto a que, es menor el consumo energético al disminuir los requerimientos de refrigeración de los reactores, como consecuencia de la elevación de temperatura que se produce por las reacciones exotérmicas que tienen lugar ${ }^{[25}$ y 26].

Los microorganismos termófilos moderados tienen su rango óptimo de temperatura entre 45 y 55

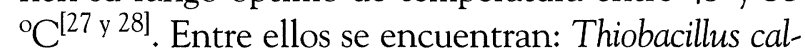
$d u s^{[29]}$, Leptospirillum thermoferrooxidans ${ }^{[30]}$, Acidimocrobium ferrooxidans ${ }^{[31]}$, Sulfobacillus thermosulfidooxidans y Sulfobacillus acidophilus ${ }^{[32}$ y 33]. Thiobacillus caldus es una bacteria autótrofa azufreoxidante, incapaz de oxidar $\mathrm{Fe}^{2+}$, por lo que ha sido utilizada en asociación con bacterias ferrooxidantes, como L. ferrooxidans, en la oxidación de concentrados de calcopirita y de $\mathrm{Zn}-\mathrm{Pb}-\mathrm{Fe}^{[19}$ y 34$]$. Lepstospirillum thermoferrooxidans es una bacteria quimioautótrofa estricta, ferrooxidante y no azufreoxidante. Posee importan- tes similitudes con Lepstospirillum ferrooxidans, pero con algunas diferencias fisiológicas y morfológicas, siendo las más importantes su temperatura óptima de trabajo, su gran resistencia a altas concentraciones de $\mathrm{Fe}^{2+}$ y su gran tamaño. Entre las bacterias del género Sulfobacillus se ha observado que $S$. thermosulfidooxidans es la más activa de las dos especies en cuanto a la oxidación de $\mathrm{Fe}^{2+}$ y de sulfuros minerales; mientras que $S$. Acidophilus es más eficiente en la oxidación de azufre. Estas especies son nutricionalmente muy versátiles al ser capaces de crecer de forma autotrófica, heterotrófica y mixotrófica (utilizando simultáneamente $\mathrm{CO}_{2}$ y glucosa) ${ }^{[33]}$.

Todas estas bacterias se han encontrado y posteriormente aislado en una gran diversidad de ambientes: drenajes ácidos de mina ${ }^{[35]}$, en la propia biolixiviación en montones de cobre ${ }^{[10]}$ y en minas de carbón ${ }^{[36]}$ o de uranio ${ }^{[37]}$. En la tabla III se muestran las principales características de los microorganismos termófilos extremos y moderados implicados en los procesos de biolixiviación.

\section{PASADO}

La biolixiviación, a pesar de ser una tecnología relativamente nueva, es un fenómeno que ha tenido lugar de forma natural desde que las bacterias y los minerales existen ${ }^{[38}$ y 39]. Remontándose a siglos atrás (100 a 200 a.C.), mucho antes del descubrimiento de las bacterias, se encuentran algunos indicios de que la biolixiviación del cobre de menas minerales se practicaba en China, e igualmente en Europa durante el siglo II d.c. ${ }^{[40]}$. En aquellos tiempos, el proceso se consideraba puramente empírico, sin llegar a asociar la acción bacteriana con la disolución de los minerales. Mucho después, a mediados del siglo XX, aparecieron los primeros artículos e informes que demostraron la implicación de las bacterias en la recuperación del cobre, al reconocerse el papel de éstas en la formación de drenajes ácidos de mina en los depósitos de carbón bituminoso $^{[41-43]}$. En 1947, Colmer y Hinkle aislaron por primera vez uno de los microorganismos más importantes en este tipo de procesos, Thiobacillus ferrooxidans, de las aguas de un depósito de carbón bituminoso, y se observó que esta bacteria era capaz de oxidar hierro y obtener energía para su metabolismo de dicho proceso de oxidación ${ }^{[44]}$.

Posteriormente, Bryner y Beck encontraron en 1954 la misma bacteria, pero esta vez en el drenaje de una mina de cobre en Bingham Canyon (Utah, EE.UU.) y demostraron, mediante experimentos de laboratorio, que $T$. ferrooxidans era capaz de 
Tabla III. Características de las bacterias termófilas con capacidad lixiviante

Table III. Thermophile bioleaching microorganisms

\begin{tabular}{|c|c|c|c|c|}
\hline Microorganismo & Tamaño y forma & $\mathrm{T}\left({ }^{\circ} \mathrm{C}\right)$ & pH & Fuente de energía quimiolitótrofa \\
\hline Leptospirillum & $1,5-3 \times 0,2-0,5 \mu \mathrm{m}$ & $30-55$ & $1,3-4,0$ & \multirow{2}{*}{ Oxida a Fe${ }^{2+}$, no $S^{0}$} \\
\hline thermoferrooxidans & Espirilo, Vibro & 45-50 óptima & 1,65-1,9 óptima & \\
\hline Sulfobacillus & $1 \times 3 \mu \mathrm{m}$ & $20-60$ & $1,9-3,0$ & \multirow{2}{*}{ Oxida a $\mathrm{Fe}^{2+}$ y $\mathrm{S}^{0}$} \\
\hline thermosulfooxidans & Bacilo & 45-50 óptima & 1,9-2,4 óptima & \\
\hline Sulfolobus & $0,8-1,0 \mu \mathrm{m}$ & $55-85$ & $1,0-5,9$ & \multirow{2}{*}{ Oxida $S^{0}$} \\
\hline acidocaldarius & Coco & 70-75 óptima & 2-3 óptima & \\
\hline Sulfolobus & $0,8-2,0 \mu \mathrm{m}$ & $50-89$ & $3-5$ & \multirow[t]{2}{*}{ Oxida a $\mathrm{Fe}^{2+} y \mathrm{~S}^{0}$} \\
\hline sulfatarius & Coco & 75-87 óptima & & \\
\hline Acidianus & $1,0-1,5 \mu \mathrm{m}$ & $45-75$ & $1,0-6,0$ & \multirow{2}{*}{ Oxida a $\mathrm{Fe}^{2+}$ y $\mathrm{S}^{0}$} \\
\hline brierleyi & Coco & 70 óptima & 1,5-,2,0 óptima & \\
\hline Sulfobacillus & $6-10 \times 0,5 \mu \mathrm{m}$ & $45-50$ & $1,0-6,0$ & Oxida a $\mathrm{Fe}^{2+}{\text { y } \mathrm{S}^{0}}$ \\
\hline acidophilus & Bacilo & & & \\
\hline
\end{tabular}

lixiviar varios sulfuros de cobre, así como molibdenita (esta última en presencia de pirita) ${ }^{[45-47]}$. En 1955, Zimmerley, Wilson y Prater fueron los primeros en patentar un proceso de biolixiviación en pilas de concentrados de cobre y cinc para el beneficio de concentrados de titanio y de concentrados mixtos de cobre-molibdeno-cromo ${ }^{[2]}$. Este proceso ha sido explotado comercialmente por la Kennecott Copper Corporation desde los años 60 para la biolixiviación de menas de baja ley y material residual de cobre. En 1964, Ehrlich demostró que T. ferrooxidans era capaz de oxidar arsenopiritas. Igualmente, durante los años 60 se ensayó la biolixiviación de otros sulfuros minerales tales como $\mathrm{ZnS}, \mathrm{NiS}$ y $\mathrm{PbS}{ }^{[48-50]}$.

Resumiendo la evolución que tuvo el proceso de investigación y desarrollo de los procesos de biolixiviación entre los años 60 y 70, destacan las siguientes aportaciones:

- Se describió la ruta metabólica de oxidación de azufre y hierro en thiobacilli, y de las interacciones bacteria-mineral.

- Se identificaron las características morfológicas y estructurales de la bacterias lixiviantes.

- Se descubrieron y caracterizaron parcialmente las bacterias termófilas extremas y moderadas, capaces de oxidar compuestos reducidos de azufre y de hierro.

- Se realizaron estudios para determinar las variables que afectaban al proceso (concentración de hierro y metales, presión, $\mathrm{pH}$, temperatura, nutrientes celulares, requerimientos de oxígeno y $\mathrm{CO}_{2}$ ).

- Se ampliaron las posibilidades de la biolixiviación hacia la recuperación de metales a partir de diversas fuentes (concentrados minerales, sulfuros minerales complejos) y hacia la eliminación de contaminantes (pirita en el carbón).

- Se estudió la ecología de las operaciones de biolixiviación de cobre en pilas y se determinó la acción de microorganismos heterótrofos en estos procesos.

- Se estudió la biolixiviación en reactores de sulfuros minerales y se realizaron pruebas para evaluar la biolixiviación de cobre a gran escala.

Todos estos estudios se encuentran recopilados en los Congresos Internacionales de Biohidrometalurgia de los años $70^{[51-54]}$, y en el libro "Microorganismos termófilos y la vida a altas temperaturas". ${ }^{[55]}$

$\mathrm{Al}$ comienzo de los años 80 ya había en funcionamiento 12 plantas de lixiviación estática de minerales de cobre en Rusia, España, México, Japón, E.E.U.U. y Chile. En ellas se utilizaban las técnicas de lixiviación in situ y en montones, para el beneficio de minerales con leyes entre 0,14 y $0,8 \%$ de cobre, con recuperaciones entre un 18 y un $60 \%$ de cobre, y una producción anual entre 900 y $13.600 \mathrm{t}$ de cobre al año ${ }^{[56]}$.

Posteriormente, en los años 80 , se realizaron numerosos e importantes avances en cuanto a la genética, las bases microbiológicas, la búsqueda de 
nuevos microorganismos, el uso de cultivos mixtos, el estudio del mecanismo de biolixiviación de la calcopirita, estudios de comportamiento electroquímico, catálisis con plata, estudios de biolixiviación con microorganismos termófilos extremos, pruebas de biolixiviación de diversos metales y conglomerados minerales (níquel, cadmio, manganeso, tierras raras, silicatos y bauxitas), biooxidación de piritas y arsenopiritas conteniendo oro, modelamiento cinético de los procesos de biolixiviación, diseño de bioreactores, y desarrollo y puesta en funcionamiento de plantas comerciales de biolixiviación y biooxidación. Todos estos avances han sido presentados en los cuatro Simposios Internacionales de Biohidrometalurgia realizados en la década de los $80^{[57-60]}$.

Como consecuencia de los avances logrados, a partir de 1986 se pusieron en funcionamiento varias plantas industriales para la extracción de cobre por biolixiviación de mineral submarginal (con menos del 0,25 \% de cobre). La compañía Gencor, en Sudáfrica, puso en funcionamiento la primera planta para el pretratamiento de minerales refractarios de oro (la planta Fairview) con el proceso $\mathrm{BIOX}^{\circledR[61]}$ y, desde esa primera aplicación comercial, se han llegado a construir varias plantas comerciales de las mismas características en los años
90. Estas plantas de biooxidación difieren de las de biolixiviación en que los microorganismos cumplen un papel de preparación del mineral catalizando la degradación del sulfuro (normalmente piritas y arsenopiritas) que contiene el oro, antes de su tratamiento químico convencional.

\section{PRESENTE}

Los años 90 fueron una época muy fructífera para estos procesos ya que, durante esta década, comenzaron a funcionar 14 de las 16 plantas comerciales existentes en la actualidad (Tablas IV y V) ${ }^{[62 \text { y 63]. }}$ Esta importante actividad comercial ha generado un gran auge investigador y se han conseguido notables hallazgos en este campo, principalmente en lo que se refiere a la bioquímica de estos procesos, a aspectos moleculares y genéticos de los microorganismos participantes en ellos y al desarrollo del aspecto económico e ingenieril de la biolixiviación y biooxidación en pilas y reactores agitados. Estos avances se encuentran recopilados en nume-

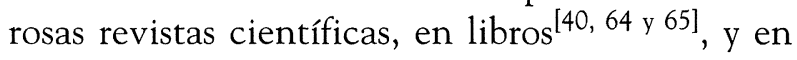
diversos simposios dedicados a la divulgación de los procesos biohidrometalúrgicos ${ }^{[66-74]}$.

La Sociedad Minera Pidahuel fue la primera en desarrollar un proceso de biolixiviación de cobre

Tabla IV. Plantas comerciales de biolixiviación de minerales de cobre (1) [62 y 63] $^{6}$

Table IV. Commercial copper bioleaching plants ${ }^{(1)}$

\begin{tabular}{|c|c|c|c|}
\hline Planta & Tamaño (t mineral/d) & Tecnología & Años de operación \\
\hline Lo Aguirre, Chile & 16.000 & Bio-Pilas con SX/EW ${ }^{(2)}$ Proceso SMP(3) & $1980-1996$ \\
\hline Gundpowder's Mammoth Mine, Australia & in situ ${ }^{(4)}$ & Proceso propio & 1991 - hoy \\
\hline Mt. Leyshon, Australia & 1.370 & Proceso Mt. Leyshon & 1992 - en cierre \\
\hline Cerro Colorado, Chile & 16.000 & Bio-Pilas con SX/EW ${ }^{(2)}$ Procéso SMP ${ }^{(3)}$ & 1993 - hoy \\
\hline Girilambone, Australia & 2.000 & Proceso Girilambone & 1993 - hoy \\
\hline Ivan-Zar, Chile & 1.500 & Bio-Pilas con SX/EW ${ }^{(2)}$ Proceso SMP ${ }^{(3)}$ & 1994 - hoy \\
\hline Quebrada Blanca, Chile & 17.300 & Bio-Pilas con SX/EW ${ }^{(2)}$ Proceso SMP ${ }^{(3)}$ & 1994 - hoy \\
\hline Andacollo, Chile & 10.000 & - & 1996 - hoy \\
\hline Dos Amigos, Chile & 3.000 & - & 1996 - hoy \\
\hline Zaldivar, Chile & $\approx 20.000$ & - & 1998 - hoy \\
\hline
\end{tabular}

\footnotetext{
(1) Datos actualizados hasta 1999.

(2) Biolixiviación en pilas, con recuperación del cobre mediante extracción con disolventes y electrólisis.

(3) Desarrollado por la Sociedad Minera Pudahuel S.A.

${ }^{(4)} \approx 1,2$ millones de toneladas de mineral.
} 
Tabla V. Plantas de biotratamiento de minerales refractarios de oro ${ }^{(1)}$ [62 y 63]

Table V. Commercial biooxidation plants for the treatment of gold refractory ores ${ }^{(1)}$ [62 y 63]

\begin{tabular}{lclc}
\hline \multicolumn{1}{c}{ Planta } & Tamaño (t mineral/d) & \multicolumn{1}{c}{ Tecnología } & Años de operación \\
\hline Fairview, South Africa & 35 & Reactores agitados Proceso BIOX ${ }^{(2)}$ & $1986-$ hoy $^{(3)}$ \\
Sao Bento, Brasil & 150 & Reactores agitados Proceso BIOX ${ }^{(2)}$ & $1990-$ hoy \\
Harbour Lights, Australia & 40 & Reactores agitados Proceso BIOX ${ }^{(2)}$ & $1992-1994$ \\
Wiluna, Australia & 115 & Reactores agitados Proceso BIOX ${ }^{(2)}$ & $1993-$ hoy \\
Ashanti's Sansu, Ghana & 1.000 & Reactores agitados Proceso BIOX ${ }^{(2)}$ & $1994-$ hoy \\
Youanmi, Australia & 120 & Reactores agitados Proceso BacTech & $14)$ \\
\hline
\end{tabular}

\footnotetext{
(1) Datos actualizados hasta 1999.

(2) Desarrollado por Genmin Process Research GENCOR, Johannesburgo, Sudáfrica.

(3) Abierta en 1986 y ampliada en 1991 a 35 t/día.

(4) Desarrollado por BacTech Ltda, Perth, Australia.
}

en pilas a escala industrial (SMP) y la técnica que estos desarrollaron en la Planta de Lo Aguirre (Chile) fue llamada Thin Layer Leaching ${ }^{[75-77] . ~}$ Esta técnica de biolixiviación consiste en la trituración del mineral a un tamaño de menor de 9 mm, aglomeración con ácido sulfúrico concentrado y lixiviación en biopilas de $2 \mathrm{~m}$ de altura. En, aproximadamente, $18 \mathrm{~d}$ de proceso se obtiene una solución de lixiviación con un $45 \%$ del cobre del concentrado. Posteriormente, una parte del concentrado lixiviado se coloca de nuevo en montones de 5-6 $\mathrm{m}$ y se lixivia durante $180-250 \mathrm{~d}$ para obtener una recuperación del $50 \%$ del cobre contenido en éste. Posteriores desarrollos en Lo Aguirre han conducido a la optimización del proceso con el tratamiento del mineral en una simple etapa, en biopilas de $6 \mathrm{~m}$ de altura, durante un período de 6 a 12 meses. Con la experiencia adquirida en esta planta, SMP ha estado asesorando el desarrollo de nuevas plantas de biolixiviación, entre las que se encuentran la Planta de Quebrada Blanca y Cerro Colorado (Chile) (Tabla IV).

En cuanto a la biolixiviación de calcopirita en reactores, se han realizado numerosos esfuerzos para la investigación de un proceso comercialmente viable, logrando durante los últimos años algunos avances en cuanto al diseño de reactores y mejoras del proceso mediante el uso de bacterias termófilas moderadas. En 1998, se puso en marcha un ensayo piloto de biolixiviación en tanques agitados en las minas de cobre de Mt. Lyell en Australia, que demostró la viabilidad técnica y comercial de estos sistemas $^{[78 \text { y } 79]}$.
Igualmente, se ha logrado avanzar en el desarrollo de nuevos procesos como el proceso IBES (Indirect Bioleaching with Effects Separation ${ }^{[80 \text { y } 81]}$ desarrollado en la Universidad de Sevilla, que ofrece considerables mejoras en las cinéticas de disolución de metales. En él se considera que el único papel de las bacterias es la regeneración del agente lixiviante $\left(\mathrm{Fe}^{3+}\right)$, por lo que se separan las etapas química (lixiviación) y biológica del proceso (biooxidación), de tal forma que se producen altas concentraciones de $\mathrm{Fe}^{3+}$ mediante la acción bacteriana en un primer reactor $y$, posteriormente, estas soluciones férricas se ponen en contacto con la calcopirita para su lixiviación en un segundo reactor. Estas dos etapas realizadas por separado ofrecen mayores ventajas: por un lado, se previene el efecto abrasivo y posterior lisis celular que conlleva la agitación en un medio sólido-bacteria, lo que hace posible el tratamiento de altas densidades de pulpa; por otro lado, es posible optimizar la acción biológica y química por separado, permitiendo utilizar las temperaturas y los $\mathrm{pH}$ más adecuados en cada caso. Otro proceso de iguales características es el proceso BRISA (Biolixiviación Rápida Indirecta con Separación de Acciones) ${ }^{[82]}$, que es un desarrollo posterior del proceso IBES, con la diferencia de que se añade ion $\mathrm{Ag}^{+}$como agente catalizador en la etapa de lixiviación química. Este proceso permite acelerar aún más las cinéticas de proceso, disminuyendo con ello los tiempos de tratamiento.

La utilización de ion $\mathrm{Ag}^{+}$en la biolixiviación de calcopirita abre nuevas expectativas en el 
tratamiento de concentrados de cobre para los cuales, la lenta cinética como consecuencia de la pasivación de la calcopirita, hace difícil su implantación a nivel industrial. Las investigaciones realizadas con bacterias mesófilas indican una elevada disolución de cobre. El mecanismo de lixiviación en presencia de plata ha sido estudiado tanto en ausencia ${ }^{[83]}$ como en presencia de bacterias ${ }^{[84-86]}$ y se produce a través de la formación de sulfuro de plata sobre la calcopirita. Dicho sulfuro se descompone en presencia de ion férrico, liberándose de nuevo $\mathrm{Ag}^{+}$capaz de seguir reaccionando con más calcopirita. Las bacterias mesófilas participan en esta catálisis suministrando $\mathrm{Fe}^{3+}$ y oxidando el azufre elemental formado.

En cuanto al tratamiento de concentrados refractarios de oro, se han realizado numerosos esfuerzos durante los últimos años en la busqueda de procesos comercialmente viables, logrando con ello el desarrollo de procesos tales como el $\mathrm{BIOX}^{\circledR}$ y el BachTech. El proceso BIOX ${ }^{\circledR[61]}$, desarrollado por la GENCOR S.A. Ltda., ha sido un éxito tanto técnico como económico y está siendo utilizado para el tratamiento de concentrados refractarios de oro (Tabla V). Este proceso consiste en una primera etapa de biooxidación del concentrado, en reactores agitados, para degradar su matriz refractaria, utilizando un cultivo mixto de bacterias mesófilas (T. thiooxidans, T.ferrooxidans y L. ferrooxidans), en un rango de temperaturas entre los 40 y $45^{\circ} \mathrm{C}$ y, en una segunda etapa, se realiza la cianuración del residuo obtenido para recuperar el oro. La compañía BachTech Ltda. (Australia) fue la primera en desarrollar y comercializar un proceso de biolixiviación en reactores agitados utilizando bacterias termófilas moderadas ${ }^{[87]}$, que fue utilizado durante el periodo comprendido entre los años 1994 y 1998 para la oxidación de concentrados refractarios de oro en la Mina de Youanmi en Australia (Tabla V). También se ha estudiado la viabilidad de este proceso en el tratamiento de sulfuros como calcopirita, y de concentrados polimetálicos complejos para la biolixiviación de níquel y cobalto. El uso de bacterias termófilas moderadas en este proceso, permite alcanzar altas velocidades de oxidación del sulfuro a la vez que se minimizan los requerimientos de refrigeración del proceso.

La recuperación de níquel a partir de sulfuros minerales de baja ley se puso en marcha en 1997, cuando GENCOR S.A. desarrolló el proceso BioNIC ${ }^{\circledR[88]}$, a partir del proceso BIOX ${ }^{\circledR}$ desarrollado por esta misma compañía para el tratamiento de concentrados refractarios de oro. En este proceso se utiliza el mismo cultivo mixto de bacterias mesófilas utilizado en el proceso $\mathrm{BIOX}^{\circledR}$, adaptado a temperaturas entre 40 y $45^{\circ} \mathrm{C}$ y a altas concentraciones de arsénico, hierro y bajos $\mathrm{pH}$. Se puede lograr una total disolución de pentlandita, calcocita, covellita, bornita y enargita. La viabilidad del proceso se logró con la puesta en marcha de una planta piloto de biolixiviación para el tratamiento de un concentrado de pentlandita en Randburg (Sudáfrica) con una producción de 20 $\mathrm{Kg} / \mathrm{d}$ de níquel.

En 1998, GeoBiotics Inc. desarrolló el proceso Geocoat $^{\text {TM [89] }}$ para dar solución a dos de los principales problemas de los procesos de biolixiviación en pilas: la obstrucción de las líneas de aire y de líquidos por partículas finas de mineral y de otros materiales, y el limitado contacto del mineral con el aire, la solución de lixiviación y las bacterias. Para ello desarrollaron una tecnología en la que se recubren soportes (rocas) de un tamaño determinado con el concentrado a biolixiviar, de tal forma que se logre optimizar su contacto con los agentes de lixiviación durante su tiempo de estancia en las biopilas. En este proceso se obtienen rendimientos de extracción del $94 \%$ de cobre en 90 d, en una calcopirita recalcitrante, utilizando bacterias termófilas a $70^{\circ} \mathrm{C}{ }^{[90]}$.

\section{FUTURO}

En cuanto a la proyección futura de los procesos biohidrometalúrgicos, la biooxidación de concentrados refractarios de oro y de cobre en reactores ha desviado el enfoque de la investigación y desarrollo en este campo hacia la mejora de los procesos en tanques agitados, a su optimización, a la disminución de los costes de capital y de operación y al aumento de sus aplicaciones ${ }^{[62]}$. Así, en un futuro próximo cabe esperar un gran desarrollo de los procesos de biolixiviación en tanques agitados, de una amplia gama de sulfuros de cobalto, galio, molibdeno, níquel, cinc y plomo ${ }^{[88 \text { y } 91-93]}$. De todos ellos, el proceso de recuperación de níquel será probablemente el primero en ser implantado a escala industrial, puesto que ya se ha desarrollado el proceso BioNIC ${ }^{\circledR}$ para la extracción de este metal a partir de sulfuros minerales de baja ley. También la biolixiviación de cobalto a partir de concentrados piríticos está muy cerca de ser comercializada, puesto que se ha completado ya el diseño del proyecto Kasese en la mina Kilembe en Uganda ${ }^{[92]}$. En este sentido, se prevee la utilización de la biolixiviación como pretratamiento de 
una gran gama de sulfuros minerales que contienen metales del grupo del platino $(\mathrm{Pt}, \mathrm{Rh}, \mathrm{Ru}, \mathrm{Pd}$, Os y Ir) ${ }^{[94]}$.

A pesar de los avances logrados, hay otras áreas en las que aún queda mucho por hacer. Cabe destacar:

a) La realización de estudios más exhaustivos sobre la compleja flora presente en los sistemas de biolixiviación: su composición, las interacciones entre los diferentes componentes de esta microflora, y sus cambios con el tiempo y con las condiciones de los sistemas de biolixiviación, tanto estática como en reactores. Los avances en este campo contribuirían a una mejora de estos procesos a través del conocimiento de cómo los componentes de estos sistemas interactúan.

b) El desarrollo de investigaciones en la búsqueda del verdadero mecanismo que hace posible la biolixiviación de concentrados minerales con el fin de poder actuar sobre la cinética del proceso.

\section{Agradecimientos}

Los autores desean expresar su agradecimiento a la Comisión Interministerial de Ciencia y Tecnología (CICYT) por la financiación de la investigación del grupo autor de este trabajo. Igualmente uno de los autores (Y. Rodríguez) desea expresar su agradecimiento a la Agencia Española de Cooperación Internacional (AECI) por la beca de estudios de Doctorado que éste organismo le concedió.

\section{REFERENCIAS}

[1] R.F. DeCKER, Met. Trans. 17A (1986) 5-29.

[2] S.R. Zimmerley, D.G Wilson y J.D. Prater, Patente de EE.UU. № 2.829.964 (1958).

[3] D.P. Kelly y A.P. Harrison, Bergey's Manual of Systematic Bacteriology, vol. 3, J.T. Staley, M.P. Bryant, N. Pfenning y col. (Eds.), Williams and Wilkins, Baltimore, E.E.U.U., 1989, pp. 1.842-1.858.

[4] H.L. EHrLiCH, J. Bacteriol. 86 (1963).

[5] A.I. López-Archilla, I. Marín y R. Amils, Biohydrometallurgical Processing, vol. 2, T. Vargas, C.A. Jerez, K.W. Wiertz y H. Toledo (Eds.), Universidad de Chile, Santiago, Chile, 1995, pp. 63-74.

[6] D.B. Johnson y F.F. RoberTo, Biomining: Theory Microbes and Industrial Processes, D.E. Rawlings (Ed.), SpringerVerlang, Berlín, Alemania, 1997, pp. 259-279.

[7] A.P. Harrison, Ann. Rev. Microbiol. 38 (1984) 265-278.
[8] R. Hallmann, A. Friedrich, H.P. Koops, A. POMMERENING-RÖSER, C. ZENNECK y W. SAND, Geomicrobiol. J. 10 (1993) 193-205.

[9] A. Ballester, Minería Química, E. Llorente (Ed.), Instituto Tecnológico Geominero de España, Madrid, 1991, pp. 485-543.

[10] C.L. BRIERLEY, CRC Crit. Rev. Microbiol. 6 (1978) 207-262.

[11] D.G. Lundgren y M. SiLver, Ann. Rev. Microbiol. 34 (1980) 263-283.

[12] D.P. Kelly, P.R. Norris y C.L. Brierley, Microbial Technology: Current State and Future Prospects. A.T. Bull, D.G. Ellwood y C. Ratledge (Eds.), Cambridge University Press, Cambridge, Inglaterra, 1979, pp. 263-275.

[13] A.A. Dispirito y O.H. TuOvinen, Arch. Microbiol. 133 (1982) 28-32.

[14] A.M. Nielsen y J.V. Beck, Science 175 (1972) 1.124-1.126.

[15] T. Sugio, Y. TsujITA y K. InAGaki, Appl. Environ. Microbiol. 56 (1990) 693-708.

[16] T. Sugio, K. Hirayama y K. Inagaki, Appl. Environ. Microbiol. 58 (1992) 1.768-1.779.

[17] P.H. Tedesco, L.B. DeCordo y A.A. Piro, Rev. Metal. Madrid 26 (1990) 151-167.

[18] T. DOnATI, G. CURUTChet y S. PORR, World J. Microbiol. Biotechnol. 8 (1992) 305-319.

[19] P.R. NoRRIs, Microbial Mineral Recovery, H.L. Ehrlich y C.L. Brierley (Eds.), McGraw-Hill, Nueva York, EE.UU., 1990, pp. 3-16.

[20] C.L. Brierley y J.A. Brierley, Can. J. Microbiol. 19 (1973) 183-198.

[21] T.D. Brock, K.M. Brock, R.T. Belly y R.L. Weiss, Arch. Microbiol. 84 (1972) 54-68.

[22] A. Segerer, A. Neuner, J.K. KristjAnsSON et al., Int. J. Syst. Bacteriol. 36 (1986) 559-564.

[23] P.R. NORRIS y J.P. OWEN, Harnessing Biotechnology for the 21 st Century, M.R. Ladish y A. Bose (Eds.), American Chemical Society, 1992, pp. 445-458.

[24] J.A. BRIERLEY, Appl. Environ. Microbiol. 36 (1978) 523-537.

[25] P.C. MilleR, Biomining: Theory Microbes and Industrial Processes, D.E. Rawlings (Ed.), Springer-Verlang, Berlín, Alemania, 1997, pp. 81-102.

[26] P.R. NORRIS, Biomining: Theory Microbes and Industrial Processes, D.E. Rawlings (Ed.), Springer-Verlang, Berlín, Alemania, 1997, pp. 247-258.

[27] P.R. NorRIS y D.W. BARR, FEMS Microbiol. Lett. 28 (1985) 221-224.

[28] P.R. Norris, L. Parrot y R.M. Marsh, Biotechnol. Bioeng. Symp. (1986) 253-262

[29] K.B. Hallberg y E.B. Lindström, Microbiology 140 (1994) 3.451-3.465.

[30] R.S. Golovacheva, O.V. Golyshina y G.I. Karavaiko, Mikrobiologiya 61 (1993) 744-750.

[31] D.A. Clark y P.R. NorRIS, Microbiology 142 (1996) 785 790. 
[32] R.S. GolovacheVA y G.I. Karavaiko, Mikrobiologiya 48 (1979) 658-667.

[33] P.R. Norris, D.A. Clark, J.P. Owen y S. Waterhouse, Microbiology 142 (1996) 775-788.

[34] B.M. Goebel y E. Stackebrandt, Appl. Environ. Microbiol. 60 (1994) 1.614-1.622.

[35] E. GÓMEZ, A.I. LÓPEZ y I. MARÍN, Biohydrometallurgical Technologies, A.E. Torma, M.L. Apel y C.L. Brieley (Eds.), The Minerals, Metals \& Materials Society, Warrendale, PA., EE.UU., 1993, pp. 479-488.

[36] R.M. MARSH y P.R. NorRIS, FEMS Microbiol. Lett. 17 (1983) 311-319.

[37] T. Fuchs, H. Huber y K. Teiner, Syst. Appl. Microbiol. 18 (1995) 560-571.

[38] E.C. Perkins y F. Novielli, Bacterial Leaching of Manganese Ores, Report of Investigations № 6.102, Bureau of Mines, Dept. Interior EE.UU., Washington DC, EE.UU., 1962.

[39] A.E. TormA, Adv. Biochem. Eng. 6 (1977) 1-37.

[40] G. Rossi, Biohydrometallurgy, Mc Graw Hill, Nueva York, EE.UU., 1990.

[41] A.R. Colmer, K.L. Temple y M.E. Hinkle, J. Bacteriol. 59 (1950) 317-328.

[42] K.L. Temple y A.R. Colmer, J. Bacteriol. 62 (1951) 605 611.

[43] W.W. Leathen, S.A. Braley y L.D. Mcintyre, Appl. Microbiol. 1 (1953) 65-75.

[44] A.R. COlmer y M.E. Hinkle, Science 106 (1947) 253-256.

[45] L.C. Bryner, J.V. BeCK, D.B. Davis y D.G. Wilson, Ind. Engin. Chem. 46 (1954) 2.587-2.592.

[46] L.C. Bryner y R. ANDERson, Ind. Eng. Chem. 49 (1957) 1.721-1.732.

[47] L.C. BRYNeR y A.K. Jameson , Appl. Microbiol. 6 (1958) 281-287.

[48] E.E. Malout y J.D. Prater, J. Met. 13 (1961) 353-364.

[49] W.E. Razzell y P.C. Trussell, Appl. Microbiol. 11 (1963) 105-116.

[50] M. Silver y A.E. Torma, Can. J. Microbiol. 20 (1974) 141-147.

[51] W. SCHWARTZ, Conference Bacterial Leaching 1977 - GFB Monograph № 4, Weinheim, Verlag, Chemie, 1977.

[52] L.E. Murr, A.E. Torma y J.A. Brierley, Metallurgical Applications of Bacterial Leaching and Related Microbiological Phenomena, Academic Press, Nueva York, EE.UU., 1978.

[53] P.A. Trudinger, M.R. Walter y B.J Ralph, Biogeochemistry of Ancient and Modern Environments, Australian Academy of Science, Australia, 1980.

[54] Proceedings of International Conference on the Use of Microorganisms in Hydrometallurgy, Hungarian Academy of Sciences, Hungría, 1980.

[55] T.D. BRock, Thermophilic Microorganisms and Life at High Temperatures, Springer-Verlag, Nueva York, EE.UU., 1978.

[56] L.E. Murr, Miner. Sci. Eng. 12 (1980) 121-189.
[57] G. Rossi y A.E. TORMA, Recent Progress in Biohydrometallurgy, Associazione Mineraria Sarda, Iglesias, Italia, 1983.

[58] R.W. Lawrence, R.M.R. BRanion y H.G. EBNER, Fundamental and Applied Biohydrometallurgy, Elsevier, Amsterdam, Holanda, 1986.

[59] P.R. NoRRIS y D.P. Kelly, Biohydrometallurgy, Kew Surry, Science and Technology Letters, 1988.

[60] J. Salley, R.G.L. McCready y P.L. Wichlacz, Biohydrometallurgy-CANMET SP89-10, Canada Centre for Mineral Recovery, McGraw-Hill Publishing Company, Canadá, 1990.

[61] P.C. Van Aswegen, Proc. Biomine '93, Australian Mineral Foundation, Adelaida, Australia, 1993 Cap. 15.

[62] C. BRIERLEY, Biomining: Theory Microbes and Industrial Processes, D.E. Rawlings (Ed.), Springer-Verlang, Berlín, Alemania, 1997, pp. 5-17.

[63] J.A. BRIERLEY y C. BRIERLEy, Proc. IBS'99, Biohydrometallurgy and the Environment Toward the Mining of the $21^{\text {st }}$ Century, A. Ballester y R. Amils (Eds.), España, 1999, pp. 81-90.

[64] H.L. Ehrlich y C.L. Brierley, Microbial Mineral Recovery, Ed. McGraw-Hill Publishing Company, Nueva York, EE.UU., 1990.

[65] D.E. Rawlings, Biomining: Theory Microbes and Industrial Processes, Springer-Verlang, Berlín, Alemania, 1997.

[66] G.I. Karavaiko, G. Rossi y Z.A. Avakyan, Biohydrometallurgy-Proceedings of an International Seminar on Dump and Underground Bacterial Leaching of Metals from Ores, Moscow, Centre of International Projects, U.R.S.S. State Committee for Environment Protection, U.R.S.S., 1990.

[67] J.C. DUARTE y R.W. LAWRENCE, IX International SymposiumBiohydrometallurgy'91, Troia, Frobitec Editions, 1991.

[68] A.E. TORMA, J.E. Wey y V.L. LAKSHMANAN, Biohydrometallurgical Technologies, vol. I, Bioleaching Processes, The Minerals, Metals \& Materials Society, Warrendale, PA., EE.UU., 1993.

[69] A.E. TORmA, M.L. APEL y C.L. BRIERley, Biohydrometallurgical Technologies, vol. II, Fossil Energy Materials, Bioremedation, Microbial Physiology, The Minerals, Metals \& Materials Society, Warrendale, EE.UU., 1993.

[70] Proc. BIOMINE'93, Application of Biotechnology to the Minerals Industry, Australian Minerals Society, Adelaida, Australia, 1993.

[71] Proc. BIOMINE'94, Application of Biotechnology to the Minerals Industry, Australian Minerals Society, Adelaida, Australia, 1994.

[72] T. Vargas, C.A. Jerez, K.W. Wiertz y H. Toledo, Proc. Biohydrometallurgical Processing, Universidad de Chile, Santiago, Chile, 1995.

[73] Proc. IBS'97 Biomine'97, Australian Mineral Foundation, Adelaida, Australia, 1997. 
[74] A. BAllester y R. Amils, Proc. IBS'99, Biohydrometallurgy and the Environment Toward the Mining of the $21^{\text {st }}$ Century, El Escorial, España, 1999.

[75] J.R. BURGER, Engineering and Mining Journal, 1985.

[76] M.S. Bustos, Copper Sulphides Ores, Copper'91, Canadá, 1991.

[77] S. Bustos, S. Castro y R. Montealegre, fems Microbiol. Rev. 11 (1993) 231-243.

[78] M. Rhodes y V. Deeplaul, Proceedings of the ALTA 1998 Copper Sulphides Symposium, Brisbane, Australia, 1998.

[79] P.C. Miller y R. Winby, SME Annual Meeting, Denver, EE.UU., 1997, pp. 94-97.

[80] F. Carranza, N. Iglesias, R. Romero e I. Palencia, FEMS Microbiol. Rev. 11 (1993) 129-138.

[81] I. Palencia, F. Carranza, F. Barriga y M.J. García, Patente Española № 2009104-8803370 (1989).

[82] F. Carranza, I. Palencia y R. Romero, Hydrometallurgy 44 (1997) 29-42.

[83] J.D. Miller, P.J. McDonough y H.Q. Portillo, Soc. Min. Eng.- AIME 27 (1981) 327-339.

[84] A. Ballester, F. GonzÁlez, M.L. BlázQuez, C. Gómez y J.L. MIER, Hydrometallurgy 29 (1992) 145-160.

[85] L. AHONEn y O.H. TUOVINEN, Hydrometallurgy 24 (1990) 219-236.

[86] A. BALlester, Separation Processes in Hydrometallurgy, G.A. Davies (Ed.), Ellis Horwood, Chichester, 1987, p. 99-112.
[87] J.R. Buddgen y M. Bunyard, Proc. BIOMINE'94, Application of Biotechnology to the Minerals Industry. Australian Minerals Society, Adelaida, Australia, 1994.

[88] D.W. DEW y D.M. Miller, Proc. IBS'97 Biomine'97, 1997, Australian Mineral Foundation (Eds.), Glenside S.A., Adelaida, Australia. Cap. M7.1.1.

[89] W. Kohr, Patente de EE.UU. № 5.766.930, 1998.

[90] C. Johansson, V. Shrader, J. Suissa, K. Adutwum y W. KOHR, Proc. IBS'99, Biohydrometallurgy and the Environment Toward the Mining of the $21^{\text {st }}$ Century, A. Ballester y R. Amils (Eds.), España, 1999, p. 569.

[91] A. SAndström, J.E. Sundkvist y S. Petersson, Proc.IBS'97 Biomine'97, Australian Mineral Foundation (Eds.), Glenside S.A., Adelaida, Australia, 1997 Cap. M1.1.1.

[92] A.P. Briggs y M. Millard, Proc. IBS'97 Biomine'97, Australian Mineral Foundation (Eds.), Glenside S.A., Adelaida, Australia, 1997 Cap. M2.4.1.

[93] M.L. Steemson, F.S. Wong y B. Gobel, Proc. IBS'97 Biomine'97, Australian Mineral Foundation (Eds.), Glenside S.A., Adelaida, Australia, 1997.

[94] H.L. EHRLICH, Biomining: Theory Microbes and Industrial Processes, D.E. Rawlings (Ed.), Springer-Verlang, Berlín, Alemania, 1997, pp. 129-150. 